\title{
ELDERS AS CONDUITS FOR INDIGENOUS LANGUAGE AND CULTURE: PROMOTING RESILIENGE AND OFFSETTING HISTORICAL OPPRESSION
}

BY CATHERINE E. MCKINLEY AND KRISTINA S. LAUKAITIS

\section{ABSTRACT}

The disruption of language and cultural traditions has been one of the most devastating casualties of historical oppression, which may give rise to health disparities. The purpose of this decolonizing critical ethnography was to use the Framework of Historical Oppression, Resilience, and Transcendence (FHORT) to explore the roles that tribal language and the oral tradition, elders, and family may play in wellness and resilience. Thematic analysis of qualitative data from a sample of 436 participants across two tribes in the U.S. revealed a strong grounding in tribal language(s) and elders as the conduits for language and culture as critical themes. 


\section{INTRODUCTION}

Western and Indigenous notions of health and mental health differ, with Indigenous peoples tending to view historical oppression and the devastating, chronic, and intergenerational disruptions in cultural practices brought on by colonization as driving forces for negative physical, social, and behavioural health disparities (in contrast to the more isolated and compartmentalized views of health in conventional approaches) (King, Smith \& Gracey, 2009). Despite treaty agreements between the U.S. government and the 567 federal sovereign tribes (known as American Indian and Alaska Natives or Native Americans, who for the purpose of this article will be identified as Indigenous peoples of the U.S. ${ }^{1}$ ) as stipulated by the U.S. Bureau of Indian Affairs (Bureau of Indian Affairs, 2017) to provide for the health and wellness of Indigenous peoples of the U.S. (U.S. Commission on Civil Rights, 2004), disparities ${ }^{2}$ persist across physical ${ }^{3}$, mental (e.g. substance abuse, post-traumatic stress disorder (PTSD), depression, and suicide (Burnette \& Cannon, 2014; Burnette \& Figley, 2017; Sarche \& Spicer, 2008)) and social dimensions.

Scholars link disparities to the context of historical oppression, which is broader (i.e., also includes contemporary trauma and oppression) but inclusive of historical trauma. Historical oppression describes the chronic, pervasive, and intergenerational experiences of oppression, which, over time may be normalized, imposed, or internalized into the daily lives of many Indigenous American peoples (including individuals, families, and communities) (Burnette, 2015a; Burnette, 2015b). Kirmayer et al. (2011) state this oppression includes "deliberate human actions and policies aimed at cultural suppression, oppression, and marginalization" (Kirmayer et al., 2011, p.63).

We use the "Framework of Historical Oppression, Resilience, and Transcendence" (Burnette \& Figley, 2017) (FHORT), which proposes that historical oppression has contributed to health disparities, whereas resilience and transcendence are strikingly apparent as well (Burnette \& Figley, 2017). The FHORT (Burnette \& Figley, 2017) approaches wellness and health with a

\footnotetext{
1 Native Hawaiians are another Indigenous group of the U.S. but operate under distinct rights in relation to the U.S. government, warranting the examinations of such groups be separate.

2 Intimate partner violence (IPV) is 1.7 times higher than for non-Indigenous women (Breiding, Chen, \& Black, 2014), whereas child maltreatment is 1.5 times higher than non-Indigenous children) (US Department of Health and Human Services, 2013).

3 Indigenous peoples have, on average, a 4.4 higher mortality rate than the general U.S. population, with leading causes including cardiovascular disease (CVD), unintentional injuries (often related to violence, and substance abuse), cancer, and diabetes (Indian Health Service, 2017).
} 
non-linear and relational ontology, which includes the social environment as well as mental, spiritual, emotional, and, physical dimensions (Burnette \& Figley, 2017; Fleming \& Ledogar, 2008). Figure 1 displays this framework and how it relates to wellness and health (Burnette \& Figley, 2017; McKinley et al., 2019).

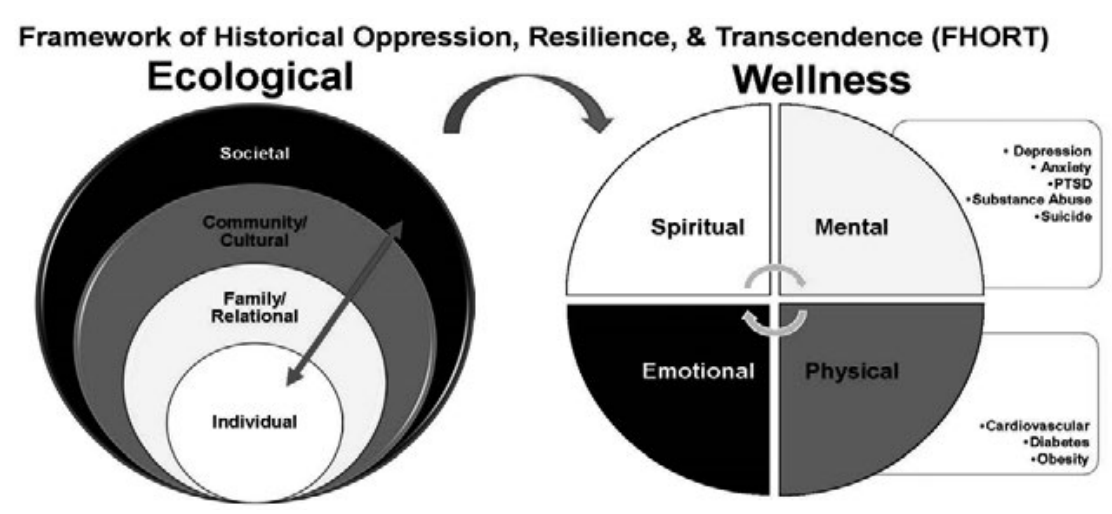

Figure 1. The Framework of Historical Oppression, Resilience, \& Transcendence (FHORT) Note. Table has been reprinted with permission from McKinley et al. (2019). The arrow represents interaction across ecological levels, which predicts whether one experiences wellness using the Medicine Wheel, and key behavioural and health outcomes.

The FHORT fills the gap in culturally based frameworks to understand resilience and wellness and address disparities (Burnette \& Figley, 2017; McKinley et al., 2019). HO expands on the prominent concept of historical trauma by being localized to specific contexts and inclusive of the proximal factors that perpetuate oppression. The balance of risk and protective factors across multiple ecological levels predicts whether a person experiences resilience, transcendence, and wellness (balance across physical, mental, emotional and spiritual health).

Historical oppression, in the forms of historical traumas (e.g., religious suppression, environmental injustice, the Boarding School Era, land dispossession, forced migration) and chronic poverty, discrimination, and marginalization is thought to be intricately connected to the health inequities experienced by Indigenous peoples (Burnette \& Figley, 2017; Wexler, 2014). The timeline of historical oppression has been comprehensively documented 
through an Indigenous lens elsewhere (See https://Nativephilanthropy.candid.org/wp-content/themes/Native-philanthropy/timeline.pdf by Walters, 2019). As indicated by this timeline, historical oppression has been legally sanctioned through governmental policies, such as the Indian Relocation Act of 1956 (also known as Public Law 959 or the Adult Vocational Training Program), which was a U.S. law intended to encourage Indigenous peoples to leave Indian reservations, acquire technical skills, and assimilate into the general population (Stubben, 2001).

The Boarding School Era was another federally sanctioned form of historical oppression, in the form of assimilationist U.S. policy (Burnette, 2015c; Haag, 2007). The curriculum of boarding schools was largely developed by Captain Richard Henry Pratt, who, in 1879 founded the notorious Carlisle school, modelled off the prison camps Pratt supervised from 1875-1878 (Haag, 2007). In 1891, the U.S. Congress funded this school and others, with other funding coming from the sale of land referred to as the 'surplus' land from the General Allotment Act of 1887, another assimilationist policy which led to massive land loss, fragmentation, and cultural loss (Haag, 2007). Boarding schools were located distances away from reservations, and children were oftentimes forcibly removed from their homes and educated in a 'Western style' (Haag, 2007). Sub-standard schools were characterized by poor ventilation, hazardous and unsanitary conditions, and no indoor plumbing. Children received poor nutrition and were made to work, stripped of identity and language, given English names, Christianized, and forbidden from speaking their tribal languages and practicing their tribal cultures (Haag, 2007). Much abuse (e.g., sexual, physical, and mental) occurred in these contexts, along with stripping Indigenous families' ability to socialize and transmit culture to their children (Burnette, 2015c; Haag, 2007).

This historical oppression has resulted in widespread disruption in families and communities, undermining parent socialization, expressions of emotional warmth, Indigenous identity, and the transmission of values, languages, and traditions (King, Smith, \& Gracey, 2009). As a result of these and numerous other federal policies, one of the greatest negative effects of historical oppression has been a breakdown of communications and language traditions across generations and relationships, known protective factors against health disparities (Goodkind, Hess, Gorman, \& Parker, 2012). Thus, rebuilding this connection is needed to repair the negative effects of such oppression (Mohatt, Fok, Burket, Henry, \& Allen, 2011). 
Both resilience and negative outcomes, such as health disparities, are documented for Indigenous peoples; however, negative outcomes gain more media attention, perpetuate negative stereotypes, and contribute to subtle forms of discrimination (Fast \& Collin-Vézina, 2010). Reasons for this imbalanced portrayal may include the necessity of demonstrating the severity of health inequalities experienced by Indigenous peoples to facilitate policy changes to address such disparities (Fast \& Collin-Vézina, 2010; US Civil Rights Commission, 2004). Yet, more bridges in research are needed to facilitate a more balanced perspective, taking into account the devastating impacts of historical oppression, while acknowledging the variability across tribes and the resilience and transcendence demonstrated by Indigenous peoples (Burnette \& Figley, 2017; Fast \& Collin-Vézina, 2010).

Research indicates that involvement, identification with, and engagement in cultural activities (i.e., enculturation) tends to be protective, or to buffer against negative behavioural outcomes (Fast \& Collin-Vézina, 2010). The denial of language and intergenerational transmission of cultural knowledge has been one of the most severe and devastating casualties of historical oppression and may give rise to health disparities. As such, the purpose of this inquiry is to examine the roles that tribal language and the oral tradition, elders, and family may play in wellness and resilience. We focus on protective factors to offset the aforementioned imbalanced portrayal of much of extant research.

\section{LANGUAGE, ELDERS, AND FAMILY TIME PROMOTING ENCULTURATION AND RESILIENCE}

Historical oppression, in its many forms, has created significant adversity; through the very act of survival and continuance, Indigenous peoples have demonstrated decolonization and resilience. Indigenous notions of resilience tend to involve holistic, complex, and interacting relationships (Kirmayer, Dandeneau, Marshall, Phillips, \& Williamson, 2011). Historical oppression is thought to have disrupted cultural continuity and awareness of Indigenous people's interconnection between the physical, mental, spiritual realms and relationships (Mohatt et al., 2011). The focus now turns to prominent forms of cultural protective factors: language, elders, and the oral tradition, which are thought to give rise to Indigenous resilience. 


\section{ELDERS AND THE ORAL TRADITION AS PROTECTIVE FACTORS}

In a review of protective factors to enhance the mental health of Indigenous youth, emphasis was placed on the importance of place and culture, as well as, history, language, and family/social support systems (MacDonald, Ford, Willox, \& Ross, 2013). Storytelling is a significant medium for transmitting knowledge inter-generationally among Indigenous cultures. The Nuu-chahnulth people residing in the Pacific coast of Vancouver Island in Canada call their tradition of storytelling and conveying community narratives of history to future generations "haa-huu-paah"(Corntassel, 2009, p.137). This experiential knowledge creates "lived values that form the basis for Indigenous governance and regeneration" (Corntassel, 2009, p.138). Indigenous storytelling traditions are significant to fostering Indigenous resilience as the foundation for Indigenous healing and rebuilding in the face of colonial oppression.

According to King et al., (2009), identity is a precursor to positive mental health, and despite experiencing historical oppression, Indigenous peoples continue to transmit knowledge, traditions, values, and language to the next generation (King et al., 2009). In Indigenous communities, elders tend to be tasked with cooperating with youth to transmit such cultural knowledge, beliefs, and principles, so that youth can translate such culture onto the contemporary social environment (Kirmayer et al., 2011). Intergenerational transmission of Indigenous worldviews and values from elders, such as discipline and spirituality (Wexler, 2014) provides psychological guidance on how to navigate oppressive policies and living conditions under colonialism, and fosters resilience among Indigenous communities.

In a qualitative study (Wexler, 2014) on cultural protective factors among three generations of the Inupiaq (an Arctic Alaskan Indigenous community), many elders described how their cultural knowledge enabled them to cope with the devastating effects of colonialism and oppression. Connection to Indigenous culture and traditions fostered less isolation and linked individuals to their greater community; elders' narratives emphasized how ideas of culture linked them to family, home, and tradition, and importantly, to feeling they were part of something intergenerational and larger than themselves (Wexler, 2014). Indeed, within an Indigenous worldview, people are often considered extensions of and integrated with families, communities, tribes, and the universe (Hill, 2006). A sense of belonging has been found to be protective for health (Hill, 2006). Thus, elders, language, and the oral tradition are important protective factors. 


\section{INDIGENOUS LANGUAGE[S] AS PROTECTIVE FACTORS FOR MENTAL HEALTH}

Cultural protective factors are important, and may include spirituality, engagement with traditional activities (enculturation), language, and healing modalities (Fleming \& Ledogar, 2008). According to Kirmayer et al., (2011), a fundamental source of Indigenous resilience is in efforts to, "revitalize language, culture, and spirituality as resources for self-fashioning, collective solidarity, and individual and collective healing (Kirmayer et al., 2011, p.89).” Indigenous languages do not simply serve a practical purpose of communication in Indigenous communities, but also affirm ethnic identity and inter-generationally transmit cultural concepts, which may not be present in Western worldviews. The Indigenous Métis people of Canada experience a strong association between their tribal language and Indigenous worldview (Iseke \& Ndimande, 2014). An elder study participant elaborated (Iseke \& Ndimande, 2014), "Because the way we speak is the way we think. ... But when you speak English, you're thinking in an English perspective...And that's not a feeling language. It's not a verb-based language, a feeling language, like the Aboriginal language" (Iseke \& Ndimande, 2014, p.154).

Out of all aspects of enculturation, Bals et al., (2011) found that the factors most associated with positive mental health outcomes were (a) knowledge of Indigenous language and (b) engagement in traditional cultural practices, which may be related to enculturation increasing self-esteem and self-efficacy while promoting group cohesiveness and mutual support (Bals et al., 2011). Research has identified that cultural continuity, or cultural resilience, buffers against suicidality - a key disparity affecting Indigenous populations (Chandler \& Lalonde, 1998; Hallett, Chandler, \& Lalonde, 2007). Hallet et al., (2007) conducted a survey of over 200 distinct Indigenous communities in Canada and found that communities with a higher level of language knowledge also had significantly lower rates of suicide among youth. Suicide rates were six times greater in the Indigenous communities with low levels of language knowledge. For communities in which at least half of its members speak the tribal language, in contrast, the youth suicide rates dropped to zero (Hallett et al., 2007). Moreover, among Indigenous Sami youth of Arctic Norway (Bals, Turi, Skre, \& Kvernmo, 2011), Indigenous language competence was found as a protective factor against anxiety and depression. The available research highlights the importance of language to promote mental health, and offset suicide, anxiety and depression, indicating the promising role of language in the promotion of wellness. 


\section{RESEARCH DESIGN}

Using the FHORT, this critical ethnography focused on culturally-relevant protective factors for Indigenous wellness. Our overarching research question was: What roles do culturally relevant protective factors, such as tribal language, the oral tradition, elders, and family, play in wellness and resilience? The scope for this study was themes related to elders, storytelling, and the oral tradition. Critical ethnographies focus on power dynamics and triangulate many forms of data, such as existing data, self-report, and direct observation (Carspecken, 1996). This decolonizing research highlights the voices of participants through the culturally relevant oral history method (Smith, 2013). Decolonizing methods embrace Indigenous knowledge and critically evaluate power inequities - transforming oppression to liberation and transcendence (Smith, 2013). We employed a decolonizing and culturally relevant relational methodology by engaging in long-term liberating research, focusing on strengths, incorporating tribal partners throughout the research process while promoting tribal self-determination and research through reciprocal relationships (Burnette, Sanders, Butcher, \& Rand, 2014). This inquiry focuses on interview data from participants across two south eastern tribes in the forms of focus groups, family interviews, and individually focused interviews.

\section{SETTING}

To enable an understanding of commonalities and differences across Indigenous populations, two tribes were included in this research process: one that is federally recognized (termed "Inland Tribe" to protect anonymity) and the other (termed "Coastal Tribe") that is state, but not federally recognized. As indicated, tribal recognition can have a substantial influence on resources, social and health outcomes, and community infrastructure. For the protection of the community identity, the names of these tribes are kept confidential. Both tribes are located in the south eastern U.S. and have enrolled tribal populations of over 10,000 members. The Inland Tribe is located several hours from the Gulf of Mexico coast. It has experienced significant economic development, with tribal schools, tribal health care and medical services, and a tribal police force, fire department, as well as health and family services. The Coastal Tribe 
is state-recognized and located in proximity to water and the Gulf Coast. The Coastal Tribe has constrained economic revenue, and the absence of federal recognition has limited the ability to develop infrastructure for tribal members. The Coastal Tribe provides employment, educational, and other individual programs for tribal members of all ages.

\section{DATA COLLECTION}

After tribal approval and local University IRB approval was gained, recruitment included posting fliers on social media, websites, in agencies, and in the community newsletter(s), along with word-of-mouth recruitment. To account for participants' time and contributions, a $\$ 20$ gift card was provided for individual and focus group interviews, whereas, families were provided a $\$ 60$ gift card. We followed a semi-structured interview guide developed to address the research questions. Following a culturally sensitive interview protocol (Carspecken, 1996), we took a life history interview approach for individually focused interviews, a component which professionals could opt into (in addition to commenting on their perspectives with working with community members). All participants who were reachable received a copy of the life history interview to keep. All study materials were geared for comprehension at ages 11 and above, or at a fifth-grade level, to account for different educational backgrounds.

\section{SAMPLE}

The sample for this study included 436 participants, which included (a) 254 individual interviews ( $n=145$ Inland Tribe; $n=109$ Coastal Tribe); (b) 217 people across 27 focus groups (113 Inland Tribe participants and 104 Coastal Tribe participants); (c)163 family interviews (80 Inland Tribe participants in 34 family interviews and 83 Coastal Tribe participants in 30 family interviews). We included 70 professionals, 105 elders $^{4}$ (55 years or older), 147 adults (24-54 years of age), and 114 youth (ages 11-23 years of age). The duration of individual interviews was about an hour (64 minutes), with family interviews lasting 70 minutes, and focus group interviews lasting almost an hour (57 minutes).

We use the term elders to be culturally congruent with the terminology used by tribal members. 


\section{DATA ANALYSIS}

Collaborative team-based data analysis was used, which included Masters of Social Work (MSW), PhD students and Indigenous tribal members from the communities included in this study (Guest \& MacQueen, 2008). After being professionally transcribed and transferred into distinct $\mathrm{NVivo}^{5}$ files for each tribe, thematic data analysis involved reading transcriptions and listening to audio files two to four times and collaboratively completing low-level coding and developing a hierarchical structure of codes and sub-codes. For interrater reliability, Cohen's Kappa coefficients were calculated (McHugh, 2012), which always exceeded the threshold (i.e., .80 or higher). Sections were examined for in-depth analysis, with interpretation of explicit and implicit meanings of data. Original categories of themes were provided to a research team of the first author's MSW students, who provided an additional layer of analysis, independently analyzing the data and bolstering the rigor and credibility of results. This article focuses on traditions and themes related to elders, language, and oral traditions. This theme was coded across 245 interviews (186 individual, 30 family, and 17 focus group interviews). The overarching themes for this article were coded across 101 Inland Tribe participants ( 79 individual, 17 family, and 5 focus group interviews) and 144 Coastal Tribe participants (107 individual, 27 family, and 10 focus group interviews).

\section{RIGOR}

A summary of results, a copy of individual interview transcripts, information about follow-up, and the opportunity to make changes to interpretations were provided to all participants who could be reached. During this member checking, no participants changed interpretations, but rather, many affirmed and extended interpretations. Results were disseminated to tribal community members on more than 10 occasions through training sessions, agency reports and presentations, presentations to tribal councils and community groups, along with facilitating community group dialogues. Research team peer debriefing occurred weekly. Consistency checks were completed by the first author throughout the interviews by encouraging participants' perspectives on thoughts and responses. Finally, 72 Inland Tribe participants (31.6\%) and 50 Coastal Tribe participants were interviewed multiple times $(24 \%)$.

\footnotetext{
5 A qualitative data analysis software program.
} 


\section{RESULTS}

Several culturally relevant protective themes emerged across tribes including: (a) A strong grounding in tribal language(s), including expressed concerns about losses of language and culture; and (b) Elders as the conduits for language and culture through storytelling and the oral tradition. Although the overarching themes are present across tribes, the specific content for some themes varied by tribe. We report results for each tribe separately under their broader themes. In total, 47 participants of the Inland Tribe spoke about language, whereas 42 from the Coastal tribe spoke about language. The number and percentage of these total participants for each theme are identified for the reader. The focus now turns to these themes.

\section{STRONG GROUNDING IN TRIBAL LANGUAGE[S]}

\section{INLAND TRIBE}

The Inland Tribe participants commonly discussed the tribal language as a significant aspect of their cultural traditions regarding communication. Thirty-two (68\%) of the Inland Tribe interviewed mentioned or discussed the tribal language. Most of the Inland Tribe interview participants described a strong grounding in their tribal language and being exposed to speaking this language in their family growing up. Several participants expressed that their first language was their tribal language and that they did not learn English until they went to school. A participant specifically described not understanding teachers when first attending an English-speaking school as a child: "We grew up in the home speaking our language. We were sent to school, my first day I did not know how to speak English and relate to the teacher." Living in an area with a large tribal community appeared to be beneficial in retaining tribal language and continuing to speak it with family and other tribal members. Those who had moved away from the Inland Tribe community had more trouble holding onto the language. A participant explained:

When we lived out of state, we only spoke English... When we moved back home is when we got our tribal language back. If we didn't move back home, I would have never gotten my language, I mean, our tribal language back. 
One participant also expressed a pride in the language and a passion to become a linguist to continue to preserve this aspect of their culture, "Wanting to become a linguist has been a part of me now, and now I feel that if I approach a non-Native or non-[tribal member] I believe in them learning a few words of my words." However, studying and preserving the tribal language appears to be complicated in that it is mostly a spoken language versus written, which hinders its preservation other than passing it down through the spoken word. A participant explained that the tribal language: “...is not a written language. It's more verbal and passed on by word of mouth." Thus, living in the tribal community offered the opportunity for exposure to the tribal language, which was not available in non-tribal cultures.

\section{CONCERNS ABOUT LOSSES OF LANGUAGE AND CULTURE.}

Several of the Inland Tribal participants expressed their concern about the loss of language and concomitant belief in the importance of passing down the tribal language to the younger generation. 15 of 47 (32\%) participants, when speaking about tribal language and culture specifically, discussed the ways in which language was transmitted to them as well as the significance of passing down the language to the younger generation. A participant emphasized, "Children need to be more taught their tribal language." Many participants expressed disappointment about how much of the younger generation is having difficulty holding on to the language. As a participant stated, "My son understands, but he basically doesn't speak it. My daughter doesn't speak either." According to study participants, it is also common for the younger generation to mix the tribal language and English in their speech. A participant describes this phenomenon, "I mean, you know, uh, that [tribal language] was my first language, and I learned English. But I think there's a lot of kids that are speaking English, or they call it '[removed for anonymity]' - mixing English and [the tribal language].”

The tribal language seems to be transmitted first through families as well as, more recently, through other institutions, such as schools. A participant asserts:

I want to see more cultural language taught in the school... I think that's taking place as of right now... Where each, um, all tribal employees must take tribal language courses... For the kids to expand their language and learn their culture. 


\section{COASTAL TRIBE}

Language appears to be a significant aspect of the Coastal Tribe's culture when it comes to traditions surrounding communication. However, because of historical oppression and cultural loss, the original tribal language of the Coastal Tribe had been replaced by a non-English colonized language with aspects of the tribal language infused into it. Tribal members tended to think of this non-English language as their tribal language and take much pride in speaking it, with 26 out of $42(62 \%)$ participants discussing language in their interviews. Nine of these $26(35 \%)$ participants specifically discussed how their tribal language was their primary spoken language growing up and that they did not learn English until they entered the school system. As a participant described, "I spoke nothing but [the] tribal language. When I went to school - I didn't speak English. So my second language is English. My first language is [the] tribal language."

\section{CONCERNS ABOUT LOSSES OF LANGUAGE AND CULTURE.}

Although language continues to be transmitted across generations, many people also spoke about loss of language and tribal ways due to historical oppression. Participants elaborated on the difficulty of integrating into the mainstream school system. Not knowing English resulted in struggling academically as well as often being harshly reprimanded by the school teacher for conversing in tribal language. One participant stated, "I failed the first grade because I wasn't speaking English.” A few study respondents described the way they would be punished in school by the teachers for speaking in the tribal language. As a participant explained, "Well if you answer a question in [the tribal language] they would hit you with a paddle or a ruler, a stick, or a branch, whatever they could get."

Although several participants discussed their fluent tribal language and the language being a significant aspect of their cultural identity, five out of $26(19 \%)$ respondents who discussed language in their interviews expressed that they did not speak tribal language. However, most of these participants had been exposed to the tribal language growing up through their family and could understand it, even if they could not speak it. A participant explained, "I understand it all. My words don't come out right. I talk to my grandma in English, she answers me in [tribal language], and we're good like that." Similarly, a participant stated: 
"Five grandkids that don't really speak [tribal language], but they understand.... All my kids do speak tribal language. Then the girls all spoke to their kids in [tribal language].”

A focus group participant stated:

Yeah and so it's up to you when you go in to either stick to [traditions] or you go with the new, but even storytelling, I'm sorry Indian people have lost a lot of their culture because of White man. Storytelling, they have to learn how to go into storytelling and develop their own stories about their tribe, about their family life, their own songs. Each community should be working on their own songs for their community and they can't say they don't have anybody to write these songs because they do.

Two additional participants discussed their thoughts around the loss of their culture. A focus group participant stated, "We'd love to get our language back, get people to learn that because it's true, we're losing our tribal language."Yet another focus group participant emphasized how ultimately, the loss of culture could mean the loss of tribal identity, and this was somewhat contingent on elders passing on language and culture to a receptive younger population. As stated: "Because once I'm gone everything's gone, you know ... Yeah. Pass on those traditions.”

\section{ELDERS AS CONDUITS FOR LANGUAGE AND CULTURE THROUGH STORYTELLING AND THE ORAL TRADITION}

As indicated, elders tended to be the primary conduits for language and culture, and the focus now turns to such themes espoused by participants.

\section{INLAND TRIBE}

The Inland Tribe participants often expressed learning about their family history, ancestors, and traditional tribal stories and myths from the elders in the community. Although, several study participants spoke about traditions being passed down through family in general, 10 out of 47 (21\%) participants described the family history as well as traditions being passed down through community elders and through elders' storytelling. Storytelling is considered 
a valuable cultural art to transmit knowledge intergenerationally, and many expressed how certain elders held reputations as storytellers in the community. One participant described her great-grandmother's gift for storytelling, "My grand great- grandmother ... they called her the famous storyteller around here." Yet another elder elaborated on the skill of storytelling espoused by her grandmother: "She is really a storyteller. She's a good storyteller, I'm not doing it justice ... but she is a huge storyteller and it's a huge gift and she is quite animated in the way she speaks."

Participants often expressed the importance of the oral history tradition in making time to sit down with grandparents and other elders in the community and listening to intergenerational folklore and stories. One participant described learning cultural traditions through directly interacting with elders of the community:

Tradition is something that ... it's morals, it's handed down, you have to sit and listen to it. You have to understand it. You have to ask me, and I'll tell you. My grandma ain't gonna [sic] text you. Sorry. If you want to talk, well then call to talk.

Speaking with elders is often the only way to receive these histories. However, participants also expressed that it is not uncommon for elders in the community to be closed off about and wary of cultural information spreading to outsiders. One participant explained how elders do not usually want their stories, folklores, or prophecies to be video- or audio-recorded:

Stories and all that. There are still people around that tells it, but they don't want to be ... exposed, because some people do believe that ... telling stories to people it might get into the wrong hands kind of thing; so a lot of our elders today are so closed because of that. Because it's one of the prophecies, I believe that once it gets into the wrong hands that person might make money off of our ways. I believe they grew up knowing that, so most people can't even allow a recorder to be laying here or video to be on them. A lot has changed.

Although the content of oral traditions may often be kept within communities, some of the participants chose to elaborate about the types of stories their grandparents and other elders told them while growing up. A participant from 
a family interview described the folk stories a friend's grandmother would tell them as children, illustrating themes of parental monitoring:

\begin{abstract}
About raccoons, just stories that ... She told us one time that it was around a lake where the Indian women used to wash the clothes, and they'd have to watch their babies because if they didn't watch their babies this big old bird used to come and snatch their babies. Sometimes the mother used to cry while the bird takes their baby up. Just little stories like that and I remember her grandmother telling us stories like that.
\end{abstract}

Participants further described the way their elders held oral history of not just general cultural myths and stories, but also information about their ancestors and their respective roles within the tribe. A participant recounted information received from family elders on the family's traditional position and roles in the society: "Yeah, like I said, my grandfather being the last war chief of the tribe ... My grandmother was ... titled a princess."

\title{
COASTAL TRBBE
}

As indicated, elder family members tend to transmit language and culture, with 14 out of 42 (33\%) study participants from the Coastal Tribe talked about the importance of elders in communicating traditions to future generations. A participant related: "I think that the elders are the people who ... [have] been through everything. Like where our history lies. I think we can learn a lot from our elders." However, this participant perceived less respect for elders as stated, "I feel like its lost respect... towards elders."

Elder communication and passing down of traditions through storytelling appears to be an informal process in the Coastal Tribe culture, that emerges in the context of spending time with grandparents or other older relatives on a regular basis. One participant explained:

I was really close to my grandpa ... Just go sit down and listen to his old stories. We would sit on the steps, me and him. He only talked tribal language ... Either we had to learn it, or just didn't understand him. I mean, I understood what he was saying, and I would talk a little bit, but not much.I used to just love going to sit there. He would 
cook pancakes for me. Just listen to his old stories about when he was growing up and stuff. It was just amazing. I miss him.

Another participant described the way she used to chat with her grandmother every night: "Well, we used to lay in bed and she would talk about the old time when she was growing up. That was very interesting... She had a lot of stories to tell." Another participant emphasized the importance of storytelling and the oral tradition:

Everyone has a story, and everyone has things that they've been through. ... My dad has some information, and he would tell it to us. Everything's pretty much passed down word-of-mouth, and that's what's messed up about the record-keeping and having the paperwork, because a lot of the Indian stuff, it was just word-of-mouth and passed down, so that's hard to prove.

\section{DISCUSSION}

Parallel to the FHORT, results reveal several culturally relevant protective factors at the family level with implications for social work with Indigenous peoples. First, despite experiencing historical oppression in varied forms, both tribes were able to retain a strong grounding in their contemporary version of their tribal language, a protective factor in its own right (Hallett et al., 2007). Although one tribe experienced the loss of their original tribal language, they were able to retain their non-English colonized language, which had aspects of their original tribal language, demonstrating adaptation, ingenuity, and resilience in response to efforts to completely assimilate them. The ability of members to retain their tribal language understandably related to the extent they were exposed to their tribal languages in their homes and communities. Tribal members who had moved away from their tribal community had a hard time retaining language customs. As such, governmental policies such as the Indian Relocation Act of 1956, not only held important ramifications in terms of communities, customs, and families, but also retention of tribal languages (Stubben, 2001). This may be an important factor to consider for urban dwelling tribal members. 
Participants across tribes also expressed experiences of first being exposed to English in grammar school, with some participants suffering academic consequences and being physically punished with a "paddle or a ruler, a stick, or a branch, whatever they could get” for speaking their tribal language. With such historical oppression and suppression of tribal language, it is not surprising that participants were concerned about the loss of tribal language and the need for language and cultural enrichment programs for youth and younger generations. Given the language loss that has occurred in some families, the transmission of knowledge through schools and community programs was recommended. Still, whether it be just understanding the tribal language and not speaking fluently, or mixing the tribal language and English, tribal language was considered an essential and prominent aspect of the tribal cultures.

Across tribes, elders were described as the primary transmitters of language and culture. Participants spoke about certain elders having a reputation as talented storytellers, the importance of oral traditions, and the relational nature of passing along cultural knowledge. Because of a history of oppression, some elders understandably protected cultural knowledge from outsiders to guard against cultural appropriation and misuse. Several participants spoke about the need for tribal members to listen to elders on their terms, to spend time with these family members, and acquire the privilege of cultural knowledge through seeking understanding. Many lessons were transmitted by elders, including illustrating parental monitoring and oversight of children through stories about animals and nature. History, family knowledge, values, social norms, and language were transmitted through elders' oral traditions and storytelling, promoting wellness.

\section{LIMITATIONS AND FUTURE RESEARCH}

Future research can investigate the topics with regard to alternative specific tribal contexts internationally. More bridges in research are needed to facilitate a balanced perspective, taking into account the devastating impacts of historical oppression, while acknowledging the variability across tribes (both urban and reservation) and the resilience and transcendence demonstrated by Indigenous peoples (Fast \& Collin-Vézina, 2010). The scope of this inquiry was limited to tribal members' perspectives on language and culture; though other themes may be relevant, they are beyond the scope of this inductive inquiry. 
Finally, future research on how such information may impact social work with Indigenous populations is warranted.

\section{CONCLUSION}

As demonstrations of the resilience and transcendence within the FHORT, culturally specific protective factors are still alive and well in these two tribal communities. Given the rapid social change, it is an important time to retain and re-envision tribal culture and language for greater transcendence. In the last generation, a rapid decline in language retention was present across tribes. Communities, families, and elders are key components to promote language and culture, and family-based programs to organically promote resilience and wellness are recommended. Given language and culture has been associated with a host of outcomes, such as suicide and substance abuse, bolstering these cultural protective factors is implicated for social work practice and to eradicate health disparities. More investigations on how to promote naturally occurring protective factors, which have offset the cultural loss imposed by historical oppression for centuries, such as through boarding schools and relocation programs, are warranted by social work researchers and practitioners. Promoting such factors is an important way to decolonize, restore, reconnect, and revitalize the extant resilience of Indigenous peoples. In closing, given that historical oppression has disrupted the intergenerational transmission of cultural knowledge, it is important to develop and support practices and community mechanisms that bridge intergenerational knowledge, which tends to include the teaching of traditions and cultural knowledge (Goodkind et al., 2012).

\section{LITERATURE}

Bals, M., Turi, A. L., Skre, I., \& Kvernmo, S. (2011). The relationship between internalizing and externalizing symptoms and cultural resilience factors in Indigenous Sami youth from Arctic Norway. International Journal of Circumpolar Health, 70(1), 37-45. https://doi.org/10.3402/ijch.v70i1.17790

Breiding, M. J., Chen, J., \& Black, M. C. (2014). Intimate partner violence in the United States -2010. Atlanta, GA: National Center for Injury Prevention and Control, Centers for Disease Control and Prevention. 
Bureau of Indian Affairs. (2017). What we do. Retrieved from https://www.bia.gov/ index.htm

Burnette, C. E. (2015a). Disentangling Indigenous women's experiences with intimate partner violence in the United States. Critical Social Work, 16(1), 1-20. http://www1.uwindsor.ca/criticalsocialwork/ DisentanglingIndigenousWomenExperiences

Burnette, C. E. (2015b). Historical oppression and intimate partner violence experienced by Indigenous women in the U.S.: Understanding connections. Social Service Review, 89(3), 531-563. https://doi.org/10.1086/683336

Burnette, C. E. (2015c). Indigenous women's resilience and resistance to historical oppression A case example from the United States. Affilia, 30(2), 235-243. https://doi.org/10.1177/0886109914555215

Burnette, C. E., \& Cannon, C. (2014). "It will always continue unless we can change something": Consequences of intimate partner violence for Indigenous women, children, and families. European Journal of Psychotraumatology, 5. https://doi.org/10.3402/ejpt.v5.24585

Burnette, C. E., Sanders, S., Butcher, H. K., \& Rand, J.T. (2014). A toolkit for ethical and culturally sensitive research: An application with Indigenous communities. Ethics and Social Welfare, 8(4), 364-382. https://doi.org/10.1080/17496535.2014.885987

Burnette, C. E., \& Figley, C. R. (2017). Historical oppression, resilience, and transcendence: Can a holistic framework help explain violence experienced by Indigenous people? Social Work, 62(1), 37-44. https://doi.org/10.1093/sw/sww065

Carspecken, P. (1996). Critical ethnography in educational research, a theoretical and practical guide. New York: Routledge.

Centers for Disease Control and Prevention. (2013). CDC health disparities and inequalities report--United States, 2013. MMWR Surveill.Summ., 62 (Suppl 3), 1-187.

Centers for Disease Control and Prevention (CDC). (2015). Summary health statistics: National health interview survey, 2014. Retrieved from https://ftp.cdc. gov/pub/health_statistics/NCHS/NHIS/SHS/2014_SHS_Table_P-1.pdf

Chandler, M. J., \& Lalonde, C. (1998). Cultural continuity as a hedge against suicide in Canada's First Nations. Transcultural Psychiatry, 35(2), 191-219. https://doi.org/10.1177/136346159803500202

Corntassel, J. (2009). Indigenous storytelling, truth-telling, and community approaches to reconciliation. ESC: English Studies in Canada, 35(1), 137-159. https://doi.org/10.1353/esc.0.0163 
Fast, E., \& Collin-Vézina, D. (2010). Historical trauma, race-based trauma and resilience of Indigenous peoples: A literature review. First Peoples Child \& Family Review, 5(1), 126-136.

Fleming, J., \& Ledogar, R. J. (2008). Resilience, an evolving concept: A review of literature relevant to Aboriginal research. Pimatisiwin, 6(2), 7-23.

Freire, P. (2018). Pedagogy of the oppressed: $30^{\text {th }}$ Anniversary Edition. New York, NY: Bloomsbury publishing.

Goodkind, J. R., Hess, J. M., Gorman, B., \& Parker, D. P. (2012). “We're still in a struggle" Diné resilience, survival, historical trauma, and healing. Qualitative Health Research, 22(8), 1019-1036. https://doi.org/10.1177/1049732312450324

Guest, G., \& MacQueen, K. M. (2008). In Guest G., MacQueen K. M. (Eds.), Handbook for team-based qualitative research. New York, NY: Altamira Press.

Haag, A. M. (2007). The Indian Boarding School Era and its continuing impact on tribal families and the provision of government services. Tulsa L.Rev., 43, 149.

Hallett, D., Chandler, M. J., \& Lalonde, C. E. (2007). Aboriginal language knowledge and youth suicide. Cognitive Development, 22(3), 392-399. https://doi.org/10.1016/j.cogdev.2007.02.001

Hill, D. L. (2006). Sense of belonging as connectedness, American Indian worldview, and mental health. Archives of Psychiatric Nursing, 20(5), 210-216. https://doi.org/10.1016/j.apnu.2006.04.003

Indian Health Service. (2017). Disparities. Retrieved from https://www.ihs.gov/ newsroom/factsheets/disparities/

Iseke, J. M., \& Ndimande, B. S. (2014). Negotiating Indigenous language narratives from Canada and South Africa: A comparative approach. International Multilingual Research Journal, 8(2), 141-166. https://doi.org/10.1080/19313152.2013.875813

King, M., Smith, A., \& Gracey, M. (2009). Indigenous health part 2: The underlying causes of the health gap. [Indigenous health part 2: The underlying causes of the health gap] The Lancet, 374(9683), 76-85. https://doi.org/10.1016/S0140-6736(09)60827-8

Kirmayer, L. J., Dandeneau, S., Marshall, E., Phillips, M. K., \& Williamson, K. J. (2011). Rethinking resilience from Indigenous perspectives. The Canadian Journal of Psychiatry, 56(2), 84-91. https://doi.org/10.1177/070674371105600203

MacDonald, J. P., Ford, J. D., Willox, A. C., \& Ross, N. A. (2013). A review of protective factors and causal mechanisms that enhance the mental health of indigenous circumpolar youth. International Journal of Circumpolar Health, 72(1), 1-18. https://doi.org/10.3402/ijch.v72i0.21775 
McHugh, M. L. (2012). Interrater reliability: The kappa statistic. Biochemia Medica, 22(3), 276-282. https://doi.org/10.11613/BM.2012.031

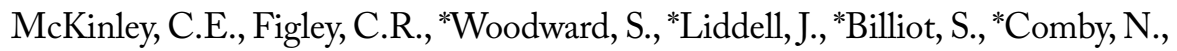
\& Sanders, S. (2019). Community-Engaged and Culturally Relevant Research to Develop Mental and Behavioral Health Interventions with American Indian and Alaska Natives. American Indian and Alaska Native Mental Health Research, 26(3), 79-103. https://doi.org/10.5820/aian.2603.2019.79

Mohatt, N. V., Fok, C. C. T., Burket, R., Henry, D., \& Allen, J. (2011). Assessment of awareness of connectedness as a culturally-based protective factor for Alaska Native youth. Cultural Diversity and Ethnic Minority Psychology, 17(4), 444455. https://doi.org/10.1037/a0025456

Sarche, M., \& Spicer, P. (2008). Poverty and health disparities for American Indian and Alaska Native children. Annals of the New York Academy of Sciences, 1136(1), 126-136. https://doi.org/10.1196/annals.1425.017

Smith, L. T. (2013). Decolonizing methodologies: Research and indigenous peoples. New York, NY. Zed Books Ltd.

Stubben, J. D. (2001). Working with and conducting research among American Indian families. American Behavioral Scientist, 44(9), 1466-1481. https://doi.org/10.1177/0002764201044009004

U.S. Commission on Civil Rights. (2004). Native American health care disparities briefing: Executive summary. Washington, DC: U.S. Commission on Civil Rights.

US Civil Rights Commission. (2004). Broken promises: Evaluating the Native American health care system. Washington, DC: US Commission on Civil Rights, US Department of Health and Human Services. (2013). Child maltreatment 2012. Retrieved from http://www.acf.hhs.gov/programs/cb/ research-data-technology/statistics-research/child-maltreatment.

Walters, K. L. (2019). History through a Native Lens. Seattle, WA: Indigenous Wellness Research Institute, University of Washington. Retrieved from https:/Nativephilanthropy.candid.org/wp-content/themes/Nativephilanthropy/timeline.pdf

Wexler, L. (2014). Looking across three generations of Alaska Natives to explore how culture fosters Indigenous resilience. Transcultural Psychiatry, 51(1), 73-92.

https://doi.org/10.1177/1363461513497417 